\title{
Organização do trabalho e a saúde mental dos trabalhadores que lidam com doação de órgãos e tecidos para transplantes
}

\author{
Work organization and mental health of workers \\ dealing with organ and tissue donation for transplants
}

Ana Rita Barreto Bernardes (https://orcid.org/0000-0002-5437-2286) ${ }^{1}$

Lucianne Sant'Anna de Menezes (https://orcid.org/0000-0002-5989-661X) ${ }^{2}$

${ }^{1}$ Hospital de Clínicas de Uberlândia, Universidade Federal de Uberlândia. Av. Pará 1720, Umuarama. 38405320

Uberlândia MG Brasil anaritabarretobernardes@ gmail.com

${ }^{2}$ Instituto de Psicologia, Universidade Federal de Uberlândia. Uberlândia MG Brasil.

\begin{abstract}
This paper presents the main results of a study developed in a Graduate Program from 2016 to 2018 with all workers from the Intra-Hospital Commission for Donating Organs and Tissues for Transplants of a Public Tertiary Hospital, in which the general proposal was to analyze the organization and the work process of this team, investigating mental strain in the workers involved. This qualitative exploratory research in $\mathrm{Oc}$ cupational Health focused on Work-Related Mental Health. The material selected for the study was retrieved by bibliographic survey, participant observation, social questionnaire, and semi-directed individual interview. It was subjected to thematic content analysis and referred to the theoretical category of mental strain. The organization and work process analysis evidenced that workers are subject to biomechanical, biological, and mental health accident risks. This condition characterizes the wear process of these workers, in particular the mental strain, which can lead to health loss. $\mathrm{Ne}$ vertheless, workers are emotionally connected to work, which can be a source of sublimation, providing pleasure and satisfaction.
\end{abstract}

Key words Occupational health, Mental health, Tissue and organ procurement
Resumo Neste artigo apresentamos os principais resultados de um estudo desenvolvido em um Programa de Pós-Graduação, entre 2016 e 2018, com todos os trabalhadores da Comissão Intra-Hospitalar de Doação de Órgãos e Tecidos para Transplantes, de um Hospital Público Terciário, em que a proposta geral foi analisar a organização e o processo de trabalho desta equipe, procurando investigar se havia desgaste mental nos trabalhadores envolvidos. Trata-se de uma pesquisa exploratória de base qualitativa no campo Saúde do Trabalhador, com foco na Saúde Mental Relacionada ao Trabalho, em que o material selecionado para o estudo, obtido por meio de levantamento bibliográfico, observação-participante, questionário social e entrevista individual semidirigida, foi submetido à análise de conteúdo temática e remetido à categoria teórica de desgaste mental. A análise da organização e do processo de trabalho demonstrou que os trabalhadores estão submetidos a riscos de acidentes, biomecânicos, biológicos e para saúde mental, quadro que caracteriza o processo de desgaste destes trabalhadores, em particular, $o$ desgaste mental, podendo levá-los a perda da saúde. Apesar disso, os trabalhadores estão afetivamente ligados ao trabalho, que pode ser fonte de sublimação, propiciando prazer e satisfação.

Palavras-chave Saúde do trabalhador, Saúde mental, Obtenção de tecidos e órgãos 


\section{Introdução}

Neste artigo apresentamos os principais resultados de uma pesquisa $(2018)^{1}$ desenvolvida com trabalhadores da Comissão Intra-Hospitalar de Doação de Órgãos e Tecidos para Transplantes (CIHDOTT), com a proposta geral de analisar a organização e o processo de trabalho, procurando investigar se havia desgaste mental nos trabalhadores envolvidos.

Nosso intuito é colaborar com as discussões no campo da Saúde Mental Relacionada ao Trabalho (SMRT), um campo especial de estudos que, na perspectiva da Saúde do Trabalhador, reconhece o processo saúde-doença relacionado ao trabalho na sua dimensão psíquica. Refere-se, portanto, à persistência dos problemas de saúde mental na conexão com o trabalho, a manifestação do sofrimento, da relação sujeito e trabalho precarizado ${ }^{2,3}$ e, necessariamente, os estudos englobam impactos patogênicos da perda de trabalho. O olhar interdisciplinar é imprescindivel para um conhecimento mais completo em SMRT, bem como uma referência valiosa para análises críticas que possam contribuir com avanços na criação de políticas públicas de prevenção nos locais de trabalho e práticas de atenção à saúde dos trabalhadores".

O trabalho precarizado é um dos efeitos do fenômeno social e mundial da precarização estrutural do trabalho que, segundo Antunes ${ }^{5}$, é uma tendência que vem sendo desenhada desde a década de 1970, quando avançou o processo de reestruturação produtiva do capital e da globalização dos mercados financeiros e, sua expansão, desde 2008, com o surgimento da nova fase da crise estrutural do capital. Este quadro delineou uma 'nova morfologia do trabalho', de modo a caracterizar o 'trabalho precarizado' fruto da lógica destrutiva do tripé 'terceirização', 'informalidade' e 'flexibilização' do trabalho imposta pelo capitalismo informacional e digital, a denominada indústria 4.0, que, no início do século XXI vem aprimorando sua engrenagem de dominação, bem como fez disparar essa processualidade, transformando a reestruturação produtiva em um processo permanente. Disso resulta uma heterogeneidade do trabalho, liquefeito e sem contornos claros, mas com o traço comum da homogeneização da tendência à precarização visível na subcontratação, terceirização e trabalho intermitente.

A organização do trabalho $(O T)$ é uma noção conceitual chave na Saúde do Trabalhador. É, por um lado, a divisão das tarefas, que se refere à distribuição, ao conteúdo das mesmas, ao modo operatório prescrito, atingindo diretamente a questão do tédio e da motivação no trabalho; e, por outro lado, a divisão dos homens, que se refere às relações interpessoais no trabalho (colegas e chefia), sendo relativa às questões da hierarquia e do poder ligados aos aspectos da dominação, submissão e servidão no trabalho. $\mathrm{O}$ segundo termo surge como complemento necessário do primeiro, tendo em vista que a gestão fixa não só uma organização técnica do trabalho e dos modos operatórios como deve verificar a execução (trabalho real) de acordo com a concepção (trabalho prescrito). Desse modo, a 'divisão dos homens' tem lugar de importância na análise dos processos psicopatológicos, tendo em vista que há uma disparidade entre o trabalho prescrito (OT formal) e a realidade concreta da execução do trabalho (OT informal). Podem ocorrer situações inesperadas como panes e acidentes, impedindo que uma tarefa seja cumprida da forma exata como foi prescrita. Dejours enfatiza que "trabalhar é preencher a lacuna entre o prescrito e o real", um caminho percorrido que deve ser inventado e descoberto pelo trabalhador a todo momento, o que implica um envolvimento da personalidade como resposta a uma tarefa delimitada por pressões ${ }^{6-8}$.

A organização do trabalho engloba as formas de avaliação, de controle sobre o trabalho, definindo assim as condições do trabalho. Há formas de organização do trabalho que atacam o funcionamento mental do trabalhador, e outras que são favoráveis à saúde dos trabalhadores. Assim, conhecendo o processo de trabalho de um determinado grupo de trabalhadores, é possível detectar as principais cargas e os traços gerais do padrão de desgaste ${ }^{4,9}$.

$\mathrm{Na}$ área de doação e transplantes, pesquisas têm sido realizadas com o intuito de investigar as cargas psíquicas as quais os profissionais de saúde estão expostos, sendo relacionadas: ao objeto do trabalho, ou seja, ao ser humano que sofre, sente dor e morre; à relação com situações estressantes e de pressão; e à organização do trabalho carreada de rotinas, burocracias, com supervisão controlada e falta de autonomia ${ }^{10-12}$.

Neste ponto, enfatizamos o conceito de desgaste, no qual Seligmann-Silva ${ }^{4}$ (p. 135), baseada em Asa Cristina Laurell, afirma que "o desgaste é visualizado como produto de uma correlação desigual de poderes impostos sobre o trabalho e sobre o trabalhador, acionando forças que incidem no processo biopsicossocial saúde-doença"; correlação de forças em que o trabalhador é per- 
dedor e sua saúde reflete estas perdas efetivas ou potenciais.

A partir desse referencial, Seligmann-Silva ${ }^{4}$ desenvolveu o conceito de desgaste mental que pode ser caracterizado em três níveis: 1) desgaste orgânico: relativo a quadros clínicos em que houve dano cerebral, por exemplo, por um acidente de trabalho ou contato com substâncias neurotóxicas; 2) desgaste funcional: relativo a variações do mal-estar como a fadiga; e 3) desgaste da subjetividade: quando a identidade do trabalhador é afetada por meio do ataque aos valores e ao caráter e engloba perdas cuja vivência leva ao sofrimento mental. A autora enfatiza que nas relações entre processo saúde-doença e processo de trabalho atuam determinações de ordem sociopolítica e econômica, que caracterizam "situações de trabalho dominado" e a desvantagem leva o corpo e os potenciais psíquicos do trabalhador (inteligência e sentimentos que se efetivam interativamente) a serem consumidos pelo processo de trabalho, advindo o desgaste que será mais grave, na medida em que a carga de trabalho e a situação de trabalho precário forem maiores.

A dicotomia vida e morte presente no cotidiano dos trabalhadores de doação de órgãos e tecidos gera conflitos, dificuldades e cargas de trabalho a que estão expostos. Estudos indicam que os profissionais da categoria de enfermagem mostram um grau significativo de ansiedade, tristeza e angústia, o que revela a necessidade de um acompanhamento psicológico. Diversos aspectos estudados evidenciam o adoecimento desses trabalhadores, dentre os quais se destacam: expressão de conceitos contraditórios em relação ao significado da morte; existência de trabalhadores que afirmam serem favoráveis à doação, porém sem a certeza de que serão doadores; o enorme sofrimento relatado quando estão com a família de um doador; falta de reconhecimento no processo de doação e transplante, bem como da padronização do serviço; falta de apoio e estrutura necessária para a excelência do processo; a tentativa de se preservar ao tentar não expor suas vulnerabilidades humanas frente a um processo de doação e transplante ${ }^{13,14}$.

O programa nacional de transplantes de órgãos do Brasil, provavelmente o maior programa público de transplantes do mundo, tem uma logística de alocação de órgãos justa e livre de qualquer privilégio social/cultural. O Sistema Nacional de Transplantes (SNT) criado pela Lei no 9.434/1997 é órgão de caráter central integrante do Ministério da Saúde, que tem tido sua organização e a legislação aprimoradas e regula- mentadas. Com isso, o sistema de doação, captação e transplantes de órgãos e tecidos ocorre de forma padronizada em qualquer ponto do território brasileiro, a fim de evitar quaisquer danos e/ou irregularidades. Portanto, há semelhança em todo o sistema. O hospital estudado está inserido nessa estrutura, assumindo papel de hospital transplantador e de fornecedor de órgãos e tecidos. As CIHDOTT são comissões dentro dos hospitais, responsáveis pela busca ativa de potenciais doadores, bem como pela organização de todo o processo de doação e captação no meio intra-hospitalar ${ }^{15-17}$.

Nesse quadro, a motivação desta pesquisa foi a preocupação com a saúde mental dos trabalhadores envolvidos no processo de doação de órgãos e tecidos para transplantes. Como está organizado o trabalho na CIHDOTT? Há desgaste mental destes trabalhadores?

\section{Metodologia}

Trata-se de uma pesquisa exploratória de base qualitativa realizada em um Hospital Público Terciário do Triângulo Mineiro, com trabalhadores da CIHDOTT, uma equipe multiprofissional ${ }^{18,19}$.

O procedimento de trabalho se dividiu em três etapas para obtenção do material a ser examinado: 1) levantamento bibliográfico realizado de 2006 a 2017, nas bases de dados SciELO, LILACS, MEDLINE, Portal CAPES, Portal de Teses e Dissertações da USP, com os seguintes descritores combinados: estresse psicológico; desgaste mental; sofrimento; saúde mental; saúde do trabalhador; esgotamento profissional; profissional de saúde; obtenção de tecidos e órgãos; carga de trabalho; transplantes; morte encefálica; doação dirigida de tecido; transplante de órgãos/tecidos; morte. Encontramos cinco livros, cinco teses, 11 dissertações e 54 artigos, dos quais selecionamos cinco livros, duas teses, três dissertações e 11 artigos, por atenderem aos critérios de inclusão conforme os objetivos da pesquisa; 2) observação -participante: 'observação descritiva'19 realizada no local de trabalho, tendo como instrumento o registro de campo (diário), em especial do ambiente, condições e processo de trabalho, no intuito de fazer uma aproximação com o processo produtivo destes trabalhadores; e 3) aplicação de questionário social e realização de entrevista individual semidirigida.

Em consonância com a Resolução $n^{\circ}$ $466 / 2012 / C N S$, que normatiza as pesquisas com 
seres humanos, a proposta foi encaminhada ao Comitê de Ética em Pesquisa e os sujeitos somente foram observados e entrevistados após a aprovação do projeto pelo CEP e da assinatura do Termo de Consentimento Livre e Esclarecido.

O material selecionado para o estudo foi submetido à análise de conteúdo temática operacionalizada em três etapas: 1) pré-análise: levantamos a hipótese inicial de que o modo como está organizado o processo de trabalho da CIHDOTT leva ao desgaste mental dos trabalhadores e criamos quatro eixos temáticos: jornada de trabalho; condições, organização e processo de trabalho; relacionamento interpessoal; sofrimento e prazer no trabalho; 2) exploração do material: leitura dialogada com a teoria, elaborando redação por temas; 3) tratamento dos resultados: os temas redigidos foram remetidos aos objetivos da pesquisa e hipótese inicial, por meio de análise interpretativa e remetidos à categoria teórica de desgaste mental e colocados em interlocução com autores da Saúde do Trabalhador, SMRT e Sociologia.

\section{Resultados e discussão}

A amostra selecionada para esta pesquisa constituiu-se pelo gênero feminino, na faixa etária de 29 a 39 anos de idade, com atuação há mais de cinco anos na área da saúde e com formação em enfermagem, assistência social e medicina, tendo em vista que a CIHDOTT pesquisada é uma equipe multidisciplinar composta por estas categorias profissionais.

\section{Jornada de trabalho}

A análise da jornada de trabalho da $\mathrm{CIH}$ DOTT permitiu identificar: plantões extras remunerados, tanto presenciais como à distância, para os períodos em que o setor não consegue cobertura com a jornada de trabalho; atender a escala quando não foi possível cobrir com plantões, de forma não remunerada, para garantir o funcionamento do setor; utilização de meios particulares (telefone próprio) para manter o serviço em funcionamento, característica do trabalho na atualidade que invade a vida pessoal do trabalhador, estendendo a jornada de trabalho, na qual o trabalhador continua parte do processo de forma voluntária à distância em casa, nos períodos descobertos de escala, também sem remuneração; trabalho em diferentes turnos pelo mesmo trabalhador, uma das formas de precarização do trabalho, presente na CIHDOTT, que leva a sobrecarga de trabalho e precarização da saúde do trabalha$\operatorname{dor}^{2,20}$ : Eu não consigo desligar. Desde que eu entrei na CIHDOTT, eu acordo e durmo com o celular ligado [...] porque eu sempre imagino que alguma coisa pode acontecer. (Camille). Se você aborda uma família já no final do plantão, você tem que dar andamento em todo o processo [...] geralmente excede o horário de trabalho. É comum. (Valéria).

Observa-se que o "papel social" da doação acaba imprimindo um peso sobre o trabalhador, que sabe que se não permanecer no trabalho além de seu horário, a doação não será efetivada e sente que precisará se desdobrar para atingir seu objetivo, que é o de salvar vidas:

Se 3 vezes na semana eu estava trabalhando a tarde, naqueles 3 dias, eu já não programava nada, ficava a disposição. [...] Eu tinha que me preparar dessa forma, [...] sempre aquele peso da responsabilidade, tipo: se eu não posso, não vai ter a doação. [...] eu não posso faltar, eu não posso adoecer. (Rogéria)

Seligmann-Silva ${ }^{21,22}$ mostra que o trabalho tem uma estrutura temporal com diferentes aspectos: duração das jornadas, distribuição em períodos diurnos e noturnos e a organização de turnos; distribuição das folgas; pausas; flexibilidade ou prescrição rígida dos ritmos. A autora ressalta que pesquisas relacionam situações de desgaste global que se expressam em envelhecimento precoce, como por exemplo, o trabalho em turno de revezamento, conforme observamos na nossa pesquisa, em que as trabalhadoras têm jornada tanto no período diurno quanto noturno, correspondendo a um envelhecimento suplementar de 7 anos em uma vida sob este regime. No trabalho noturno, segundo Rosa et al..$^{23}$, os efeitos negativos da restrição do sono podem gerar fadiga, redução do desempenho motor $\mathrm{e}$ cognitivo, alterações das atividades metabólicas, hormonais e imunológicas. Com isso, para as trabalhadoras que estendem sua jornada de trabalho sem descanso entre os turnos, observa-se declínio no desempenho em certos momentos do dia ou da noite, o que configura risco de acidentes de trabalho, podendo levar a erros nos processos de trabalho.

Soma-se ao quadro acima que, em tempos pandêmicos de COVID-19 as trabalhadoras continuam sob o mesmo regime, ou seja, não estão em trabalho remoto, tendo em vista que as atividades desenvolvidas na CIHDOTT são consideradas serviços essenciais. Moronte ${ }^{24}$ descreve este grupo como "Trabalhadores em Tempos de Guerra", pois não podem ficar reclusos em seus lares para proteger sua saúde, expondo-se a si- 
tuações de perigo e, por vezes, trabalhando em condições precárias. A necessidade de exposição ocupacional, causa medo e insegurança, assim como a manutenção destas condições leva a um processo de desgaste com condições de possibilidade de gerar sofrimento e adoecimento. Este processo de desgaste pode avançar para a manutenção de um sofrimento contínuo que acaba fazendo parte do cotidiano, podendo levar a um temerário estado de "normalidade sofredora", podendo desencadear transtornos mentais relacionados ao trabalho.

Para Gaulejac ${ }^{25}$, o gerenciamento torna-se uma "tecnologia do poder, entre o capital e o trabalho," (p.27) sendo exercido pelo ideal de qualidade que é alcançado por meio da excelência, comprometimento, sucesso, desempenho e progresso. O objetivo é conseguir a adesão dos funcionários à empresa (neste caso um hospital), cujo princípio de que a produção não pode parar (24 horas - CIHDOTT) se sobrepõe às necessidades e aos limites da condição humana desses trabalhadores, conduzindo a uma prática de jornada de trabalho prolongada, ritmo acelerado e aumentam da pressão e responsabilidades, levando à sobrecarga de trabalho e ao desgaste mental.

\section{Condições, organização e processo de trabalho}

O processo de trabalho da CIHDOTT é organizado em três fluxos de trabalho: 1) doação em casos de óbitos com coração parado; 2) doação em casos de morte encefálica e 3) tarefas administrativas, além de outras atividades como a capacitação sobre o tema doação e protocolo de morte encefálica promovida à maioria dos setores do hospital, durante o ano. O primeiro fluxo ocorre em cinco etapas: busca ativa por potenciais doadores, notificação de óbito, validação do doador, entrevista familiar e doação das córneas. Paralelamente ao processo de trabalho relacionado ao fluxo de doação de córneas, ocorre o processo relacionado ao fluxo de doação de múltiplos órgãos e tecidos, que são os casos de morte encefálica, processo que ocorre em sete etapas: busca ativa por potenciais doadores, identificação do potencial doador, protocolo de morte encefálica, validação do doador, entrevista familiar, doação de múltiplos órgãos e tecidos; e, captação e liberação do corpo para a família' ${ }^{1}$. A entrevista familiar foi considerada pelas trabalhadoras uma etapa do processo de trabalho de extrema tensão.

A divisão e operacionalização das tarefas, em especial, a discrepância entre o trabalho prescrito (tarefa) e o trabalho real (atividade efetivamente realizada), evidenciam a vivência de precarização, um dos efeitos do neoliberalismo na saúde dos trabalhadores, vivido como desgaste mental e a corrosão da subjetividade ${ }^{5,26}$. Estudos atuais mostram que o neoliberalismo é uma lógica normativa global, um sistema que ampliou sua influência ao mundo inteiro, estendendo a lógica do capital a todas as relações sociais e esferas da vida, sendo instaurado por forças e poderes que se apoiam uns nos outros em nível nacional e internacional, formando uma coalização que exerce uma função política em escala mundial, bem como define novos modos de subjetivação. Nesse sentido, não se reduz a um sistema econômico a práticas que definem o capitalismo contemporâneo na sua característica globalizada, mas, é uma forma de vida que enquanto tal compreende uma gramática de reconhecimento e uma política para o sofrimento, de modo que se pode extrair mais produção e mais gozo do próprio sofrimento ${ }^{27,28}$.

A análise das condições, organização e processo de trabalho da equipe CIHDOTT demonstrou que o trabalhador está exposto aos seguintes riscos de agravos à saúde:

1) biomecânicos: permanência prolongada em pé, grande distância percorrida, adoção de posturas inadequadas, podendo ocasionar dores, problemas de coluna e lesões físicas;

2) de acidentes: quedas da própria altura e das escadas, podendo gerar lesões corporais;

3) biológicos: vírus, bactérias, parasitas, protozoários, fungos e bacilos próprios do ambiente hospitalar, assim como pelo transporte do órgão ou tecido para o transplante, podendo gerar doenças infecto-contagiosas;

4) para saúde mental: derivados da organização do trabalho como jornada de trabalho excessiva (com destaque para os plantões extras não remunerados, em especial à distância, o que explora o trabalhador e invade sua vida privada) e dimensionamento inadequado de pessoal, que interferem no processo de trabalho, em especial, no modo operatório das tarefas, provocando alterações no ritmo e carga de trabalho, gerando sobrecarga e pressões. Associado a isso, destaca-se o cotidiano conflituoso relativo ao axioma vida e morte, principalmente, nas relações interpessoais com as famílias e na convivência com situações que geram medo e estado de alerta permanentes. Esta problemática somada aos constrangimentos cotidianos e situações de humilhação nas relações com as equipes intra e extra hospital, as falhas na logística de doação, tal como a falta de estrutura física e material, podem ocasionar so- 
frimento psíquico, irritabilidade, ansiedade, angústia, culpa, sentimento de desamparo, insônia, fadiga, alterações de comportamento e transtornos mentais. Este quadro caracteriza o processo de desgaste dos trabalhadores, em particular, o desgaste mental.

\section{Relacionamento interpessoal}

A boa relação na equipe está atrelada ao objetivo comum de trabalho: efetivar uma doação e ajudar pessoas. Foi demonstrado companheirismo e afeto, ilustração da cooperação, conforme Dejours ${ }^{9}$, uma forma de mobilização subjetiva que surge da vontade coletiva dos indivíduos de trabalharem juntos e superarem coletivamente as contradições que surgem da essência da organização do trabalho e que não funciona sem relações de confiança estruturadas pelo respeito às regras do trabalho, supondo um compromisso ao mesmo tempo técnico e social: cooperar e viver junto são indissociáveis.

As entrevistadas relataram que, para trabalhar na CIHDOTT, deve-se ter um perfil adequado, em que o trabalhador seja sensível, empático, disposto a se envolver no processo e que goste do desfecho final, ou seja, a efetivação do transplante. Relataram também a necessidade de estar sempre disponível, "comprometido o tempo todo com o trabalho", como algo natural, o que revela a questão do poder e da ideologia gerencialista em jogo nestas relações. Estar disponível o tempo todo passa a ser uma característica intrínseca ao trabalhador de transplantes de órgãos e tecidos. É a 'submissão livremente consentida', que Gaulejac ${ }^{25}$ aponta, passando do controle dos corpos para a mobilização psíquica a serviço da empresa, neste caso o hospital.

A relação interpessoal da equipe da $\mathrm{CIH}-$ DOTT com os demais setores do hospital já não é tão boa. Há setores que se articulam bem e outros não. Alguns dificultam o andamento do processo de trabalho porque não entendem ou não conhecem o processo de doação vigente e, portanto, não percebem a sua importância para a instituição e a sociedade; além de profissionais que são contra a doação. Apesar disso, a equipe busca se relacionar de modo harmônico com todos os setores do hospital.

Quanto à relação interpessoal junto à equipe externa, a Organização por Procura de Órgãos (OPO), expressa diversas dificuldades, como: demora na oferta dos órgãos; mudança de logística sem informar em tempo hábil; falta de respaldo das ações e padronização de condutas; e um gran- de entrave é fato da OPO não funcionar 24 horas, em desacordo com a Portaria no ${ }^{\circ} .2600 / 2009^{16}$.

A fim de melhorar a relação da CIHDOTT com os setores do hospital e a OPO, propomos a adoção de uma "Política de doação de órgãos e tecidos”, para padronizar as condutas relacionadas ao processo de doação, procurando impedir a interferência de opiniões pessoais como 'ser contra a doação de órgãos'.

\section{Sofrimento e prazer no trabalho}

O contato constante com pessoas doentes, lesadas, gravemente feridas e mortas impõe, ao trabalhador da saúde, uma série de atividades que abrangem tarefas agradáveis ou não, que requerem para sua execução uma constante rotina de ajustes e adequações de estratégias defensivas para o desempenho de suas tarefas que, ao lidar com a morte, gera angústia, sofrimento, dor e tristeza $^{29,30}$. Lembremos que, segundo Dejours ${ }^{31}$, as estratégias defensivas são construídas e organizadas coletivamente; funcionam como 'regras de trabalho' e surgem como forma de proteção dos trabalhadores quando a organização do trabalho entra em conflito com o funcionamento psíquico destes sujeitos, procurando impedir a emergência do sofrimento patogênico.

Tal quadro põe a descoberto a condição humana de finitude, a condição de desamparo do psiquismo frente ao aumento do fluxo pulsional com o qual, por vezes, o sujeito não consegue lidar, podendo se instalar uma situação traumática, um estado psicopatológico. Quando em presença da morte, o discurso dos trabalhadores revela o sentimento de desamparo, em torno do qual gravitam os destinos sofridos pelo fluxo pulsional, no contexto do inevitável jogo de forças entre as demandas culturais e a renúncia pulsional, como por exemplo, sentimentos de solidão, impotência, desalento, perdas, ameaça à integridade corporal, caracterizando expressões do mal-estar no campo do trabalho ${ }^{7,32,33}$.

A entrevista familiar, segundo pesquisas ${ }^{13,14}$, é considerada uma das etapas mais complexas do processo de doação, e envolve aspectos éticos, legais e emocionais. Cada família possui seus valores e crenças e por isso, não existe um roteiro a ser seguido. O trabalhador deve estar preparado para elucidar dúvidas e enfrentar diferentes situações e sentimentos, sendo este um dos momentos mais estressantes e que foi possível detectar na organização do processo de trabalho como fonte de sofrimento da CIHDOTT. O local para realização da entrevista com a família foi considerado 
fundamental, revelando o aspecto subjetivo deste espaço que interfere no acolhimento e na abordagem da família, pois quando detectado como inapropriado pelo trabalhador, gera expectativa ansiosa, revelando-se como um fator de desgaste mental.

A incerteza da decisão da família também gera sofrimento. A possibilidade da doação é um direito da família assegurado pela equipe de doação. De um lado, a torcida pelo "sim", para a autorização e aceitação da doação de múltiplos órgãos e tecidos. De outro, a possibilidade do "não" da família, que leva à frustração do trabalhador frente à não doação, vivida, por vezes, como uma falha no cumprimento de suas tarefas, gerando ansiedade, tristeza, sentimento de culpa e impotência:

Já é tão difícil ter um doador [...] e aí quando tenho eu perco? Em que compete a eu fazer, correr atrás, [...] eu tento fazer. E essa pressão eu mesma exerço sobre mim. E aí então eu experimento mais uma vez a ansiedade [...] Será que eu consegui demonstrar para a família empatia? [...] Acho que a ansiedade é pelo sim, pela doação. (Rogéria)

Durante a entrevista familiar, é estabelecido um vínculo com a família, um compromisso firmado em relação ao tempo para liberação do corpo ou mesmo quanto à utilização dos órgãos doados. Entretanto, a possibilidade de intercorrências durante a logística de distribuição de órgãos, pode atrasar o início da captação e a liberação do corpo para a família. Tal fato acaba por aumentar o tempo de espera e a ansiedade da família doadora e, consequentemente, a expectativa ansiosa da equipe de doação, que traz para si a responsabilidade da conclusão deste processo para não desapontar esta família.

Outras situações relacionadas à organização e ao processo de trabalho foram detectadas como experiências angustiantes e por vezes humilhantes para as trabalhadoras: preocupação quanto à disponibilidade dos exames para concluir o protocolo de morte encefálica; estrutura disponível insuficiente e funções não pactuadas na instituição que acabam sendo realizadas por meio de "favor" para que o processo seja concluído; falta de compromisso dos profissionais; desconhecimento do processo pelos próprios trabalhadores do hospital.

Também há vivências de sofrimento fruto da realização de jornada de trabalho excedente, que invade a vida privada do trabalhador que renuncia a sua vida pessoal, para acompanhar processos de doação fora do horário de trabalho, nos períodos noturnos sem cobertura de escala, para não perder uma doação. Cenário que ilustra a flexibilização do trabalho como base do adoecimento, na atualidade ${ }^{2,4,5,25,34}$ : A gente tem que contar com a compreensão do marido, filhos, e às vezes até datas comemorativas [...] nós abandonamos nossa família em prol de tá aqui ajudando o próximo, com esse objetivo. (Valéria)

Como enfatiza Dejours ${ }^{6}$, o psiquismo não é atingido diretamente; primeiro é vitimizado o corpo do trabalhador, disciplinado e dócil, entregue às dificuldades inerentes às atividades laborais. Cria-se um corpo amorfo, sem defesa, explorado, fragilizado e carente de seu contorno protetor: o psiquismo. Para ele, as relações de trabalho nas organizações desapossam o trabalhador de sua subjetividade, excluindo o sujeito, o que faz do homem uma vítima do seu trabalho. As trabalhadoras da CIHDOTT se queixam de cansaço geral, esgotamento, tensão nervosa, que não conseguem 'se desligar' do trabalho, o que no contexto do material selecionado para análise configura o desgaste funcional, relativo a variações do mal-estar como a fadiga:

'Esgotamento pra mim é estar muito cansada. Eu sinto cansaço mental [...] exemplo: essa captação tem que acabar logo pra eu conseguir relaxar, [...] pensar em outras coisas. Porque naquele momento, minha mente ficou o tempo todo pensando, como um disco furado. Ele vai e volta, [...] já fiz isso, já falei com os médicos, com as equipes envolvidas [...] são muitos detalhes que, por causa de uma coisa, todo o processo pode dar errado. [...] 'tipo, acaba logo porque preciso descansar a cabeça.' (Rogéria)

Quando o cansaço se acumula ao longo do tempo, ele não termina com o sono diário, o que provoca alterações no sono, irritabilidade, desânimo, dores diversas, perda de apetite, afetando o humor e a sociabilidade, leva à "fadiga crônica" ou "fadiga patológica", como enfatiza Seligmann$\mathrm{Silva}^{4,22}$. Contudo, entende-se que caso não ocorra um replanejamento do trabalho, a fim de eliminar ou minimizar os fatores de desgaste mental, não só as trabalhadoras podem ter fadiga patológica, como este quadro pode levar ao "desgaste psíquico entendido como deformação", nos dizeres de Seligmann-Silva ${ }^{4}$, em que cada vez mais será afetada a identidade (segundo o conceito de 'identidade em processo' de Peter Berger e Thomas Luckmann), por meio do ataque à dignidade e da 'corrosão do caráter' (concepção de Richard Sennett), bem como o abalo da 'economia psicossomática' (noção de Pierre Marty), levando ao desgaste da subjetividade, o terceiro nível do desgaste mental. 
Apesar das vivências de desprazer e sofrimento, elas experimentam prazer, alegria, felicidade e gratidão, tendo em vista que o trabalho da $\mathrm{CIH}$ DOTT tem sentido, gostam do que fazem. O trabalho é o fim alcançado, fruto de muito estudo, formação profissional e uma vida de renúncias. Há ligação afetiva com o trabalho, o que o torna fonte de satisfação pulsional, um meio de sublimação, destino pulsional mais elevado e fundamental para saúde mental, como nos alertou Freud $^{33}$. Nesse sentido, destaca-se a importância do trabalho como um instrumento que o homem criou para lidar com seu desamparo e viver em sociedade ${ }^{7,32,33}$.

'A motivação é o resultado do nosso trabalho, é saber das pessoas que vão ser beneficiadas, que vão receber órgãos, que vão ter qualidade de vida.' Essa é a motivação principal. E eu gosto do que eu faço. (Valéria).

O prazer e a satisfação no trabalho são experimentados quando uma família é bem acolhida e orientada, quando uma doação foi bem sucedida, portanto, é participar e fazer parte de um processo que mudou ou mudará a vida de uma pessoa e que, em consequência disso, haverá algum tipo de contribuição para a sociedade. $\mathrm{O}$ resultado final do processo de doação, o transplante, é o que mais motiva a equipe, e assim as trabalhadoras vivenciam o reconhecimento, o que possibilita que o sofrimento no trabalho possa ser transformado em prazer e realização, além de ser fundamental para a construção da identidade e da cooperação ${ }^{6}$.

Corroboram os resultados acima, as evidências de Lima et al..$^{14}$ de que o trabalhador que lida com doação de órgãos percebe que seu trabalho é extremamente dignificante, uma vez que está fazendo o bem ao próximo, promovendo vida. Segundo os autores, o trabalhador se sente importante neste processo, pois possibilita ao doador um fim digno, e para a família, informação e conforto, além de poder colaborar com a sociedade.

\section{Considerações finais}

A análise da organização e do processo de trabalho na CIHDOTT demonstrou que o trabalhador está exposto a riscos de acidentes, biomecânicos, biológicos e riscos para saúde mental, quadro que caracteriza o processo de desgaste dos trabalhadores, em particular, o desgaste funcional - fadiga, confirmando nossa hipótese de que $o$ modo como está organizado o processo de trabalho da CIHDOTT leva ao desgaste mental. E, tendo em vista que o sistema de doação, captação e transplantes de órgãos e tecidos ocorre de forma padronizada, no território brasileiro, há semelhança de todo o processo de trabalho descrito na CIHDOTT do Hospital estudado com o resto do país e, desta forma, o presente estudo ajuda a delinear um padrão de desgaste, colaborando com a prevenção de riscos de agravos à saúde dos trabalhadores desta categoria, restabelecendo a promoção e proteção da saúde, em especial, a saúde mental.

Frente a toda problemática apresentada, torna-se necessário reorganizar o processo de trabalho na CIHDOTT, com o objetivo de extinguir ou minimizar os riscos de agravos advindos das condições, organização e processo de trabalho. O replanejamento do trabalho não visa apenas melhorar as condições de saúde do trabalhador, mas também, toda a qualidade do processo e do produto final ${ }^{35}$.

Dentre as propostas de replanejamento, sugerimos a adequação do dimensionamento de pessoal para funcionamento em tempo integral, com expansão do quadro de funcionários do setor, e contratação de um auxiliar administrativo para solução das questões administrativas; a construção de um fluxo de notificação de óbitos hospitalares à CIHDOTT, evitando busca ativa contínua; a disponibilização de exames complementares para o diagnóstico de morte encefálica, diariamente; a comunicação em tempo real entre as equipes (externas e CIHDOTT); agilizar a oferta de órgãos e elaboração da logística necessária à captação; instituir reuniões mensais da CIHDOTT para discussão de casos trabalhados, detecção de pontos críticos, e até mesmo identificar sinais de adoecimento entre os trabalhadores.

Os resultados desta pesquisa vêm despertar a necessidade urgente de que os órgãos governamentais passem a constituir estratégias na área da Saúde do Trabalhador, preocupando-se em proporcionar às equipes envolvidas em todo o processo de doação, captação e transplantes de órgãos e tecidos, condições mais adequadas diante desta realidade que vivenciam rotineiramente: a morte e a vida.

Em tempos atuais da persistente tendência à precarização estrutural do trabalho em escala global ${ }^{5}$, da terceirização e flexibilização ${ }^{34}$ como base do adoecimento, como recuperar nossa emancipação $0^{36}$, no sentido habermasiano? 


\section{Colaboradores}

As duas autoras participaram da concepção do trabalho, da análise e interpretação dos dados, de sua redação, bem como da discussão dos resultados e considerações finais.

\section{Referências}

1. Bernardes ARB. Sobre o processo de trabalho da equipe de doação de órgãos e tecidos: um olhar sobre a saúde mental [dissertação]. Uberlândia: Universidade Federal de Uberlândia; 2018. p. 112.

2. Franco T, Druck G, Seligmann-Silva E. As novas relações de trabalho, o desgaste mental do trabalhador e os transtornos mentais no trabalho precarizado. Rev Bras Saude Ocup 2010; 35(122):229-248.

3. Mendes R. Patogênese das novas morfologias do trabalho no capitalismo contemporâneo: conhecer para mudar. Estudos Avançados 2020; 34(98):93-110.

4. Seligmann-Silva E. Trabalho e desgaste mental: o direito de ser dono de si mesmo. São Paulo: Editora Cortez; 2011.

5. Antunes R. O privilégio da servidão: o novo proletariado de serviços na era digital. São Paulo: Boitempo; 2018.

6. Dejours C. Subjetividade, trabalho e ação. Revista Produção 2004; 14(3):27-34.

7. Menezes LS. Psicanálise e Saúde do trabalhador: nos rastros da precarização do trabalho. São Paulo: Primavera Editorial; 2012.

8. Dejours C, Abdoucheli E, Jayet C. Psicodinâmica do Trabalho: Contribuições da Escola Dejouriana à Análise da Relação Prazer, Sofrimento e Trabalho. São Paulo: Atlas; 1997.

9. Dejours C. Addendum: Da psicopatologia à psicodinâmica do trabalho. In: Lancman S, Sznelwar LI, organizadores. Christophe Dejours: Da psicopatologia à psicodinâmica do trabalho. Rio de Janeiro: Fiocruz; Brasília: Paralelo 5; 2004.

10. Amorim SF, Bruscato WL, Martins LAW. Síndrome de Bornout em enfermeiros captadores de órgãos de doadores cadáveres para transplante: um estudo preliminar. Arq Med Hosp Fac Cienc Med Santa Casa São Paulo 2008; 1(53):1-5.

11. Secco IAO, Robazzi MLCC, Souza FEA, Shimizu PS Cargas psíquicas de trabalho e desgaste dos trabalhadores de enfermagem de Hospital de Ensino do Paraná, Brasil. Rev Eletrônica Saúde Mental Álcool e Drogas 2010; 6(1):1-17.

12. Mininel VA, Baptista PCP, Felli VEA. Cargas psíquicas e processos de desgaste em trabalhadores de enfermagem de hospitais universitários brasileiras. Rev Latino-Americana de Enfermagem 2011; 19(2):1-9.

13. Guido LA, Linch GFC, Andolhe R, Conegatto CC, Tonini CC. Estressores na assistência de enfermagem ao potencial doador de órgãos. Rev Latino-Americana de Enfermagem 2009; 17(6).

14. Lima AAF, Silva MJP, Pereira LLL. Sofrimento e contradição: o significado da morte e do morrer para enfermeiros que trabalham no processo de doação de órgãos para transplante. Rev Enfermería Global 2009; 1(15):1-16.

15. Brasil. Lei no ${ }^{\circ} .9434$, de 4 de fevereiro de 1997. Dispõe sobre a remoção de órgãos, tecidos e partes do corpo humano para fins de transplante e tratamento e dá outras providências. Diário Oficial da União 1997; $04 \mathrm{fev}$.

16. Brasil. Portaria $n^{\circ} .2600$, de 21 de outubro de 2009 . Aprova o Regulamento Técnico do Sistema Nacional de Transplantes. Diário Oficial da União 2009; 21 out. 
17. Brasil. Decreto ${ }^{\circ}$. 9.175, de 18 de outubro de 2017. Regulamenta a Lei no. 9.434, de 4 de fevereiro de 1997, para tratar da disposição de órgãos, tecidos, células e partes do corpo humano para fins de transplante e tratamento. Diário Oficial da União 2017; 18 out.

18. Bardin L. Análise de Conteúdo. Tradução de Luis Antero Reto, Augusto Pinheiro. 70a ed. São Paulo: LDA; 2011.

19. Minayo CS, organizadora. Pesquisa Social: Teoria, método e criatividade. Rio de Janeiro: Editora Vozes; 2009.

20. Antunes R, Alves G. As mutações no mundo do trabalho na era da mundialização do capital. Educação \& Sociedade 2004; 25(87):335-351.

21. Seligmann-Silva E. Saúde mental relacionada ao trabalho: as visões teóricas sob a pressão da precarização. In: Macêdo KB, organizadores. Organização do trabalho e adoecimento - uma visão interdisciplinar. Goiânia: Ed. da PUC Goiás; 2016. p. 177-198.

22. Seligmann-Silva E. Psicopatologia no trabalho: aspectos contemporâneos. In: Macêdo KB, organizadores. Organização do trabalho e adoecimento - uma visão interdisciplinar. Goiânia: Ed. da PUC Goiás; 2016. p. 209-237.

23. Rosa PLFS, Fischer FM, Borges FNS, Soares NS, Rotenberg L, Landsbergis P. Percepção da duração do sono e da fadiga entre trabalhadores de enfermagem. Rev Enfermagem da UERJ 2007; 15(1):100-106.

24. Moronte EA. A pandemia do novo coronavírus e o impacto na saúde mental dos trabalhadores e trabalhadoras. In: Augusto BC, Santos RD, organizadores. Pandemias e pandemônio no Brasil. São Paulo: Tirantlo Blanch; 2020. p. 219-228.

25. Gaulejac V. Gestão como doença social: ideologia, poder gerencialista e fragmentação social. São Paulo: Idéias e letras; 2007.

26. Druck G, Franco T. A perda da razão social do trabalho: terceirização e precarização. São Paulo: Boitempo; 2007.

27. Dunker CIL. Mal-estar, sofrimento e sintoma: uma psicopatologia do Brasil entre muros. São Paulo: Boitempo; 2015.
28. Dardot P, Laval C. A nova razão do mundo: ensaio sobre a sociedade neoliberal. (M. Echalar, Trad.). São Paulo: Boitempo; 2016.

29. Pitta AMF. Hospital: dor e morte como ofício. São Paulo: Hucitec; 1999.

30. Oliveira EVM. Aspectos sociais e subjetivos na representação da morte: implicações laborais aos profissionais que lidam diariamente com a morte. Contribuciones a las Ciencias Sociales [periódico na Internet]. 2011 Jun. [acessado 2020 abr 20]; 12(6):[cerca de 8 p.]. Disponível em: https://www.eumed.net/rev/cccss /12/evmo.htm

31. Dejours C. A loucura do trabalho: estudo da psicopatologia do trabalho. Tradução de Ana Izabel Paraguay e Lucia Leal Ferreira. São Paulo: Cortez Editora; 2015.

32. Menezes LS. Desamparo. $2^{\circ}$ ed. São Paulo: Casa do Psicólogo, Coleção Clínica Psicanalítica; 2012.

33. Freud S. O mal-estar na civilização - novas Conferências Introdutórias a Psicanálise e outros textos (19301936). In: S Freud S. Obras Completas. v. 18. São Paulo: Companhia das Letras; 2010.

34. Druck G. Flexibilização e precarização: formas contemporâneas de dominação do trabalho. Caderno CRH 2002; 37:11-22.

35. Sato L. Prevenção de agravos à saúde do trabalhador: replanejando o trabalho através das negociações cotidianas. Cad Saude Publica 2002; 18(5):1147-1166.

36. Habermas J. Conhecimento e interesse. Tradução de José Nicolau Heck. Rio de Janeiro: Guanabara; 1987.

Artigo apresentado em 20/04/2020

Aprovado em 02/08/2021

Versão final apresentada em 04/08/2021

Editores-chefes: Romeu Gomes, Antônio Augusto Moura da Silva 